\title{
Guanethidine and Related Agents
}

\author{
III. ANTAGONISM BY DRUGS WHICH INHIBIT THE \\ NOREPINEPHRINE PUMP IN MAN
}

\author{
Jerry R. Mrtchell, John H. Cavanaugh, Luis Arias, and \\ John A. OAtes \\ From the Division of Clinical Pharmacology, Departments of Medicine and \\ Pharmacology, Vanderbilt University School of Medicine, \\ Nashville, Tennessee 37203
}

A B S T R A C T Antagonism of the antihypertensive action of guanethidine by the tricyclic antidepressants, desipramine and protriptyline, has been demonstrated in controlled studies. These antidepressants also prevent the effect of the related ring-substituted guanidinium adrenergic neuron blockers, bethanidine and debrisoquin. That the rise in blood pressure when desipramine is added to guanethidine therapy is not due simply to a pressor action of the two drugs in combination was demonstrated by the lack of an increase in blood pressure when guanethidine was added to desipramine therapy.

Investigations were conducted to determine whether antagonism of guanethidine's clinical effect could result from blockade by the tricyclic antidepressants of the norepinephrine pump in the adrenergic neuron membrane, thereby preventing the uptake of guanethidine into the neuron by this pump. Like guanethidine, the indirectly acting pressor amine, tyramine, enters the neuron via the norepinephrine pump. Desipramine, protriptyline, and amitriptyline in clinical doses all were found to block the pressor action of tyramine while potentiating the pressor effect of norepinephrine. The amino acid, methyldopa, does not enter the neuron via the norepinephrine pump, and its antihypertensive action is not altered by concomitant administration of tricyclic antidepressants. It is concluded from the evidence in this investigation together with the results of previous studies in experimental animals that clinical doses of desipramine-like drugs inhibit the norepinephrine

This work was presented in part to the Southern Society for Clinical Investigation, 1 February 1969, and in a preliminary communication (1).

Received for publication 22 July 1969 and in revised form 22 February 1970. pump in the peripheral adrenergic neuron in man and thereby prevent uptake of guanethidine to its site of action.

\section{INTRODUCTION}

Observations by Leishman, Mathews, and Smith (2) suggested that imipramine may block the effect of guanethidine in hypertensive patients. Studies in experimental animals also have shown that imipraminelike antidepressants will prevent some of the actions of guanethidine $(3,4)$. Because of the notion that there is a relation between the psyche and hypertension, the use of such psychotherapeutic agents in the hypertensive population is widespread. Accordingly, studies were undertaken to obtain data on the clinical significance of interactions between these drugs and guanethidine, and to determine whether similar interactions occurred with the related guanidinium antihypertensives, bethanidine and debrisoquin. The possibility that the antagonism resulted from an inhibition of transport of these antihypertensives to their site of action was investigated.

\section{METHODS}

The studies were conducted in the Clinical Research Center of Vanderbilt University Hospital and in the Nashville Veterans Administration Hospital.

Demonstration of drug antagonism. 13 hypertensive adults (10 men and 3 women) were placed on a regular hospital diet containing $100 \mathrm{mEq}$ of sodium per day. These patients when hospitalized had persistent hypertension of moderate to severe degree; on admission their blood pressures while standing ranged from 190 to $250 \mathrm{~mm} \mathrm{Hg}$ in systole and 115 to $160 \mathrm{~mm} \mathrm{Hg}$ in diastole. Four patients intermittently had mild azotemia (blood urea nitrogen, 30-50 mg/100 ml) but none had liver disease. All medica- 
TABLE I

Interactions between Antihypertensive and Antidepressant Drugs in Patients

\begin{tabular}{|c|c|c|c|c|c|}
\hline \multirow[b]{2}{*}{ Patient } & \multirow[b]{2}{*}{ Antihypertensive drug and dosage } & \multirow[b]{2}{*}{ Antagonist drug and dosage } & \multicolumn{3}{|c|}{$\begin{array}{l}\text { Average of mean blood pressures } \\
\text { in the standing position } \pm \mathrm{SE}\end{array}$} \\
\hline & & & $\begin{array}{c}\text { Pre- } \\
\text { antagonist } \\
\text { priod }\end{array}$ & $\begin{array}{l}\text { Antagonist } \\
\text { period }\end{array}$ & $\begin{array}{c}\text { Post- } \\
\text { antagonist } \\
\text { period }\end{array}$ \\
\hline L. L. C. & Guan, $150 \mathrm{mg}$ daily, 31 days & $\begin{array}{l}\text { DMI, } 75 \mathrm{mg} \text { daily, } 3 \text { days } \\
\text { then } 125 \mathrm{mg} \text { daily, } 6 \text { days }\end{array}$ & $93 \pm 3^{*}$ & $116 \pm 3$ & $94 \pm 5^{*}$ \\
\hline D. C. W. & Guan, $100 \mathrm{mg}$ daily, 19 days & DMI, $50 \mathrm{mg}$ daily, 2 days & $112 \pm 5 \ddagger$ & $138 \pm 2$ & $114 \pm 1 \ddagger$ \\
\hline T. D. P. & Guan, $150 \mathrm{mg}$ daily, 18 days & DMI, $75 \mathrm{mg}$ daily, 1.3 days & $108 \pm 3^{*}$ & $130 \pm 5$ & $98 \pm 4 \ddagger$ \\
\hline L. J. & Guan, $60 \mathrm{mg}$ daily, 20 days & DMI, $75 \mathrm{mg}$ daily, 5 days & $103 \pm 4^{*}$ & $128 \pm 3$ & $108 \pm 5 \S$ \\
\hline J. H. D. & Guan, $70 \mathrm{mg}$ daily, 18 days & DMI, $75 \mathrm{mg}$ daily, 3.3 days & $103 \pm 4 \S$ & $119 \pm 3$ & $107 \pm 1 \S$ \\
\hline G. T. E. & Guan, $220 \mathrm{mg}$ daily, 30 days & DMI, $150 \mathrm{mg}$ daily, 9 days & $101 \pm 4 \ddagger$ & $116 \pm 1$ & $111 \pm 5$ \\
\hline E. L. & Guan, $50 \mathrm{mg}$ daily, 9 days & Pro, $20 \mathrm{mg}$ daily, 3.5 days & $115 \pm 5^{*}$ & $155 \pm 6$ & - \\
\hline D. C. W. & Beth, $80 \mathrm{mg}$ daily, 16 days & DMI, 50 mg daily, 1 day & $105 \pm 2^{*}$ & $142 \pm 4$ & $106 \pm 2^{*}$ \\
\hline W. R. D. & Beth, $20 \mathrm{mg}$ daily, 30 days & DMI, $50 \mathrm{mg}$ daily, 1 day & $102 \pm 3^{*}$ & $146 \pm 3$ & - \\
\hline R. H. C. & Beth, $15 \mathrm{mg}$ daily, 16 days & DMI, $75 \mathrm{mg}$ daily, 2 days & $94 \pm 4^{*}$ & $142 \pm 1$ & $126 \pm 3^{*}$ \\
\hline W. S. & Debr, $60 \mathrm{mg}$ daily, 30 days & DMI, $75 \mathrm{mg}$ daily, 1.3 days & $88 \pm 5^{*}$ & $127 \pm 3$ & $116 \pm 3 \S$ \\
\hline H. E. A. & Debr, $240 \mathrm{mg}$ daily, 29 days & DMI, $75 \mathrm{mg}$ daily, 6 days & $80 \pm 5^{*}$ & $107 \pm 1$ & $94 \pm 1^{*}$ \\
\hline L. L. B. & Meth, $3.0 \mathrm{~g}$ daily, 24 days & DMI, $75 \mathrm{mg}$ daily, 5 days & $99 \pm 4$ & $96 \pm 5$ & $100 \pm 4$ \\
\hline W. R. D. & Meth, $2.5 \mathrm{~g}$ daily, 28 days & DMI, 75 mg daily, 4.7 days & $90 \pm 4$ & $87 \pm 3$ & 一 \\
\hline E. N. & Meth, $3.0 \mathrm{~g}$ daily, 15 days & DMI, $75 \mathrm{mg}$ daily, 6 days & $104 \pm 5$ & $96 \pm 5$ & - \\
\hline
\end{tabular}

Patients receiving a clinically effective dose of guanethidine (Guan), bethanidine (Beth), debrisoquin (Debr), or methyldopa (Meth) were given desipramine (DMI) or protriptyline (Pro) as described in Methods.

* Differs from antagonist period, $P<0.005$.

$\ddagger$ Differs from antagonist period, $P<0.01$.

$\S$ Differs from antagonist period, $P<0.05$.

tions, with the exception of digitoxin in one patient, were discontinued for at least 1 wk before the experimental period. Except for the initial study (patient L. L.) placebo capsules identical in appearance and mode of administration to desipramine and protriptyline were used during pre and postexperimental control periods of the studies with guanethidine, debrisoquin, and methyldopa, in order that patients would not know when administration of the antidepressant drugs was initiated. The placebo did not raise the blood pressure.

After the clinically effective dose of one of the antihypertensive drugs (guanethidine sulfate, bethanidine sulfate, debrisoquin sulfate, or methyldopa) was determined for a patient, that dose was continued throughout the study. The total daily dose was divided into two or three doses given between 9 a.m. and 9 p.m. each day. The antihypertensive drug was administered alone in that fashion for a control period of at least 5 days before adding the proposed antagonist, desipramine hydrochloride or protriptyline hydrochloride. The antagonist was given in divided doses $30 \mathrm{~min}$ before the administration of the control doses of the antihypertensive drug. The duration of administration of the antagonist was determined by the blood pressure response. After stopping the antagonist, a postantagonist period of at least 10 days was obtained while the patient continued on the same dose of the antihypertensive drug. Doses and duration of administration are summarized in Table I.

Altogether there were seven studies on guanethidine, three on bethanidine, two on debrisoquin, and three on methyldopa (two patients were studied twice, using a different antihypertensive agent in the second study). Desipramine was the proposed antagonist in 14 of the studies, while protriptyline was given in the 15 th.

Observations on blood pressure and apical pulse rate were made at the same hour four times daily with the patient both in the supine and standing (at least $2 \mathrm{~min}$ ) positions. The effects of the drug on computed mean blood pressure (diastolic blood pressure plus one-third pulse pressure) were evaluated. The average mean blood pressure in the standing position was calculated for each day from the four daily blood pressure determinations. For statistical analysis, the average of each patient's daily mean blood pressures in the standing position for days 1 through 5 (bethanidine, debrisoquin, methyldopa patients) or days 2 through 5 (guanethidine patients) of the antagonist period was compared by the two-tailed Student's unpaired $t$ test with the corresponding data for both the preantagonist period (the 5 days preceding administration of antagonist) and days 8 through 10 of the postantagonist period (days 11 through 13 for patients G. T. E. and L.L. C. who received increased doses of antagonist). Also, single values representing the overall average of mean blood pressures for the entire preantagonist, antagonist, and postantagonist intervals as defined above were computed from the daily mean bluod pressures of patients on guanethidine. In order to be able to draw conclusions about the general population of guanethidine-treated patients on the basis of the group sampled, the interval values were statistically analyzed by comparing the group's values for the antagonist period with their values for the pre-antagonist and post-antagonist periods by the method of an individual degree of freedom for a split-plot design (5). 
Investigation of the mechanism of the antagonism. Mildly hypertensive adults (patients whose blood pressures as outpatients exceeded 140 and $90 \mathrm{~mm} \mathrm{Hg}$ in systole and diastole, respectively, but returned to the normal range without treatment upon hospitalization) and normal volunteers were placed on a regular diet. The volunteers were not required to stay in the hospital at night. The influences of desipramine, protriptyline, amitriptyline, and chlorpheniramine maleate on the norepinephrine transport system in adrenergic neurons were evaluated by studying the effects of these agents on the acute pressor responses to intravenous administration of tyramine hydrochloride and 1-norepinephrine bitartrate. Placebos were used for the antidepressants on nondrug days. Tyramine was given in acute injections with the patient supine and monitored by an oscilloscopeelectrocardiogram. Blood pressure was recorded at 30 -sec intervals by the indirect auscultatory method. Dosage was increased until the systolic pressure reached or exceeded a $25 \mathrm{~mm} \mathrm{Hg}$ rise over base line value. From dose response curves, the amount of amine necessary to increase systolic pressure by $25 \mathrm{~mm} \mathrm{Hg}$ was determined. The "sensitivity" to the pressor amine was expressed as a ratio of the average dose on control days to that obtained on the experimental day (Fig. 3). After evalution of the sensitivity to tyramine, similar dose-pressor response curves were obtained for norepinephrine, except that the pressor response was deter-

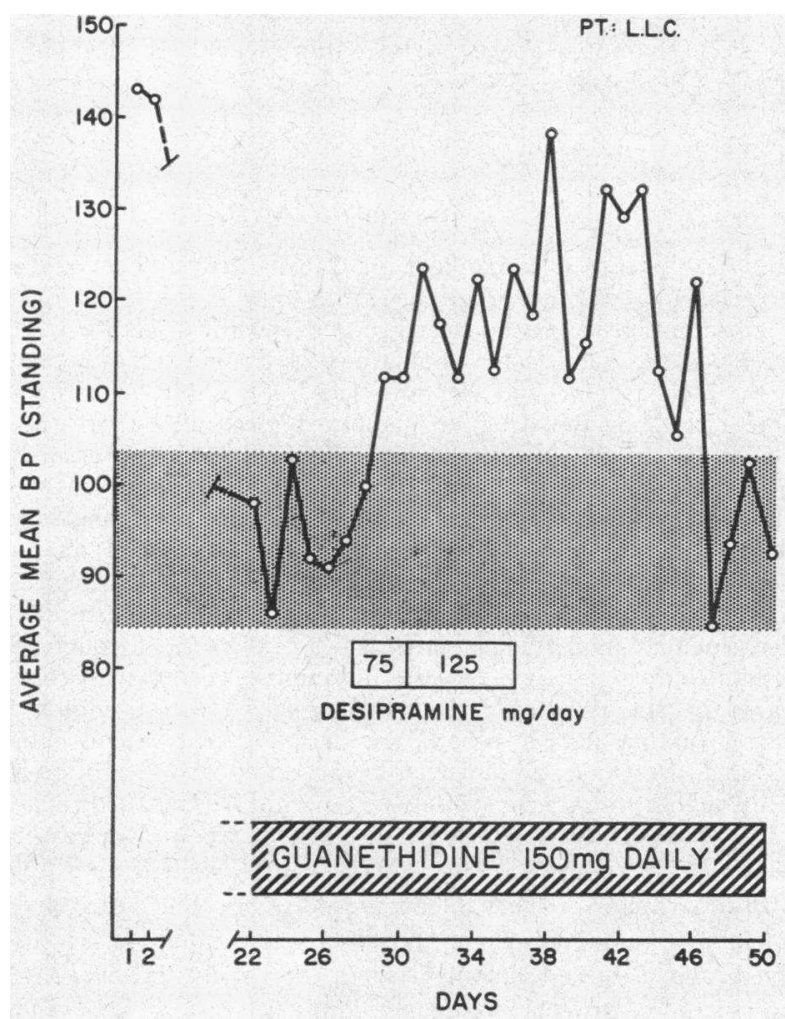

FIGURE 1 Antagonism of guanethidine by desipramine. Guanethidine was given in increasing doses until blood pressure was controlled with $150 \mathrm{mg}$ daily. This dose was maintained during the experimental period. Desipramine was administered as indicated. The shaded area defines the range of pressures during the control periods.
TABLE II

The Effect on Arterial Pressure of the Addition of Guanethidine to the Regimen of Patients Receiving Desipramine

\begin{tabular}{|c|c|c|c|}
\hline \multirow[b]{2}{*}{ Patients } & \multicolumn{2}{|c|}{$\begin{array}{l}\text { Average of mean blood pressure } \\
\text { in standing position }\end{array}$} & \multirow[b]{2}{*}{$P$} \\
\hline & $\begin{array}{l}\text { Desip- } \\
\text { ramine } \\
75 \mathrm{mg} \\
\text { daily } \\
\text { (5 days) }\end{array}$ & $\begin{array}{c}\text { Desipramine } \\
75 \mathrm{mg} \\
\text { daily plus } \\
\text { guanethidine } \\
100 \mathrm{mg} \\
\text { daily } \\
\text { (5 days) }\end{array}$ & \\
\hline A. B. & 110 & 98 & $>0.05$ \\
\hline T. H. & 113 & 110 & $>0.1$ \\
\hline F. B. & 97 & 98 & $>0.1$ \\
\hline
\end{tabular}

mined after infusion of norepinephrine for $10 \mathrm{~min}$ at a constant rate.

Additional studies were carried out to determine the effects of concomitant administration of desipramine and guanethidine on patients' pressor responses to intravenous administration of tyramine and $l$-norepinephrine. Desipramine ( $75 \mathrm{mg}$ daily) was given to three mildly hypertensive patients for 22 days and guanethidine (100 mg daily) was added on days 9-15. Pressor responses were determined on control days and on days $6-8,13-15$, and 21-22. Placebos were substituted for guanethidine as well as desipramine on nondrug days.

\section{RESULTS}

Demonstration of drug antagonism. Desipramine and protriptyline reversed the antihypertensive effects of guanethidine in every patient to a highly significant degree (Table I). The probability of obtaining a group of guanethidine-treated patients who respond in this way by random chance from the general population of patients receiving guanethidine is less than 1 in 1000 . The reversal of guanethidine's action was not immediate requiring 1 or 2 days before maximum antagonism was seen (Fig. 1).

The antihypertesnive actions of bethanidine and debrisoquin also were antagonized (Table I). The reversal of their effects was more rapid than with guanethidine, with almost maximum antagonism appearing within a few hours (Fig. 2).

In no patient receiving a guanidinium hypotensive. agent did the extent of blood pressure evaluation after administration of desipramine or protriptyline exceed that patient's blood pressure off antihypertensive medication. After discontinuation of desipramine $(75 \mathrm{mg}$ daily), 5-7 days were required for the antihypertensive actions of the guanidiniums to reappear. About 10 days were necessary for guanethidine's effect to return in the two patients (L. L. C., and G. T. W.) who received larger doses of desipramine. Two studies were terminated (E. L., and W. R. D.) without obtaining a post- 


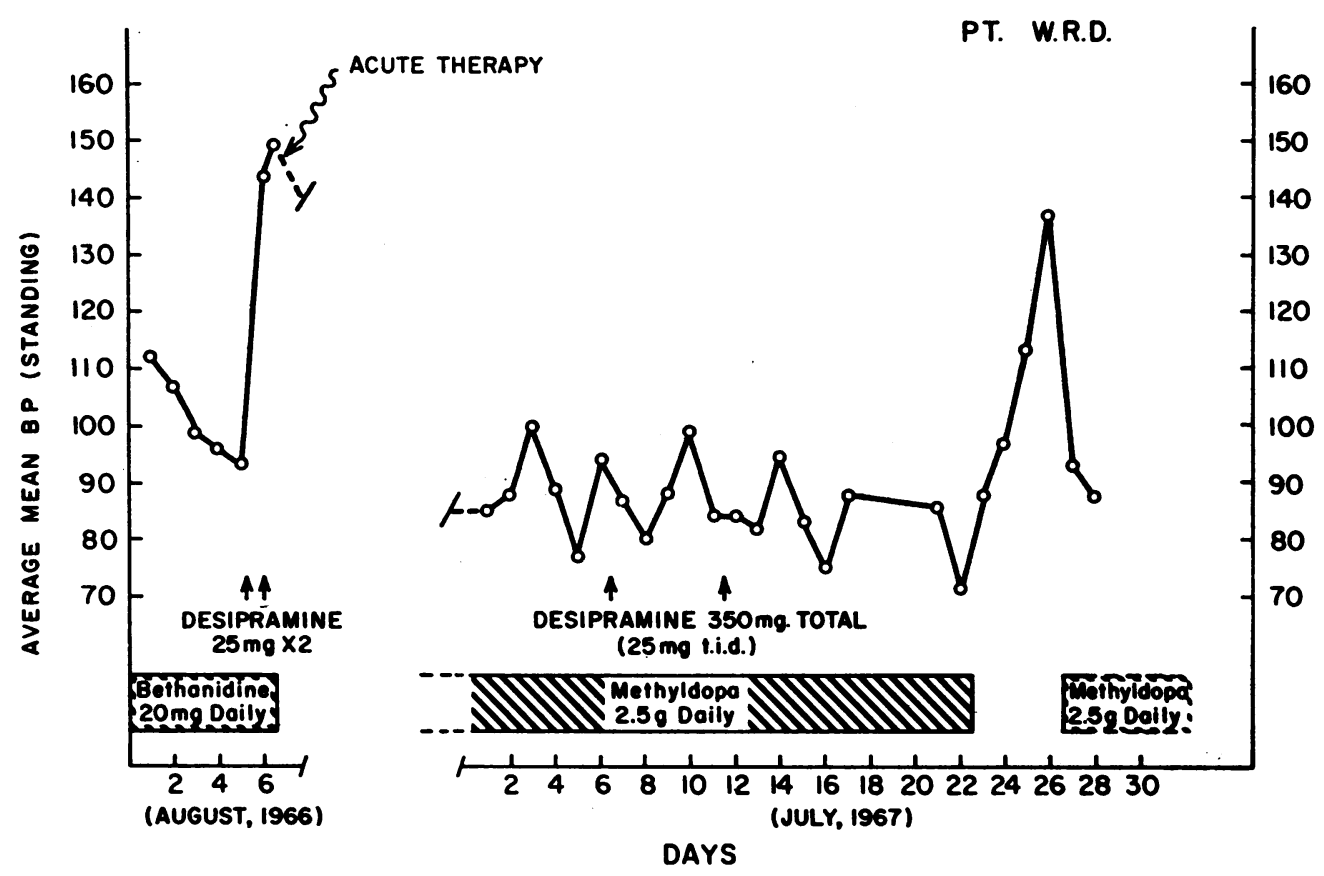

FIGURE 2 Antagonism of bethanidine and failure of antagonism of methyldopa by desipramine. Bethanidine or methyldopa was given in increasing doses until blood pressure was controlled. This dose was maintained during the experimental period. Desipramine was administered between arrows. Methyldopa was discontinued for approximately 3 days beginning $22 \mathrm{July}$ in order to demonstrate that loss of its effect in this patient would result in a rise in pressure. Acute therapy refers to the initiation of additional antihypertensive drugs to reduce the pressure at the time indicated.

antagonist period when antihypertensive drugs other than a guanidinium were required to control safely the patient's blood pressure after administration of the antidepressant.

In the three studies in which methyldopa was the antihypertensive, its action was not antagonized by desipramine (Table I, Fig. 2). Because no antagonism was demonstrated, the postantagonist period was omitted in two (W. R. D., and E. N.) of these.

Investigation of the mechanism of the antagonism. Related studies in this laboratory have demonstrated that the guanidinium antihypertensive agents reach their site of action in adrenergic neurons via a transport system in the neuron membrane. ${ }^{1}$ This is the same pump that transports norepinephrine and tyramine into the neuron. Thus, pressor responses to tyramine and norepinephrine can be used as indices of inhibition of this pump by drugs in man.

Figs. 3, 4, and 5 show that desipramine, protriptyline, and amitriptyline in eight studies reduced several-fold the pressor effect of the indirectly-acting sympatho-

${ }^{1}$ Mitchell, J. R., and J. A. Oates. 1970. Guanethidine and related agents. I. Mechanism of the selective blockade of adrenergic neurons and its competitive antagonism by drugs. J. Pharmacol. Exp. Ther. 172: 100. mimetic, tyramine, while potentiating the directly-acting norepinephrine. These effects of desipramine and amitriptyline persisted 5 or more days after stopping the antagonist, with the longest duration of effect being seen in the single study with protriptyline.

Three types of evidence were obtained to exclude the possibility that the rise in blood pressure when guanethidine was added to desipramine resulted from a marked supersensitivity to circulating norepinephrine produced by the combination of these drugs. Whereas the addition of desipramine to antihypertensive doses of guanethidine produced a rise in blood pressure in hypertensive patients, the administration of a large dose of guanethidine ( $100 \mathrm{mg}$ daily) for 5 days to three mildly hypertensive patients receiving desipramine did not raise blood pressure (Table II). Furthermore, the expected hypotensive effect of this dose of guanethidine was prevented by desipramine. In two of these patients, the pressor sensitivity to norepinephrine was measured during therapy with desipramine $75 \mathrm{mg}$ daily alone and again after 5 days on guanethidine $100 \mathrm{mg}$ daily together with the desipramine, and was not consistently changed by the addition of guanethidine (Fig. 6). Nor is the increase in pressor sensitivity to norepinephrine 


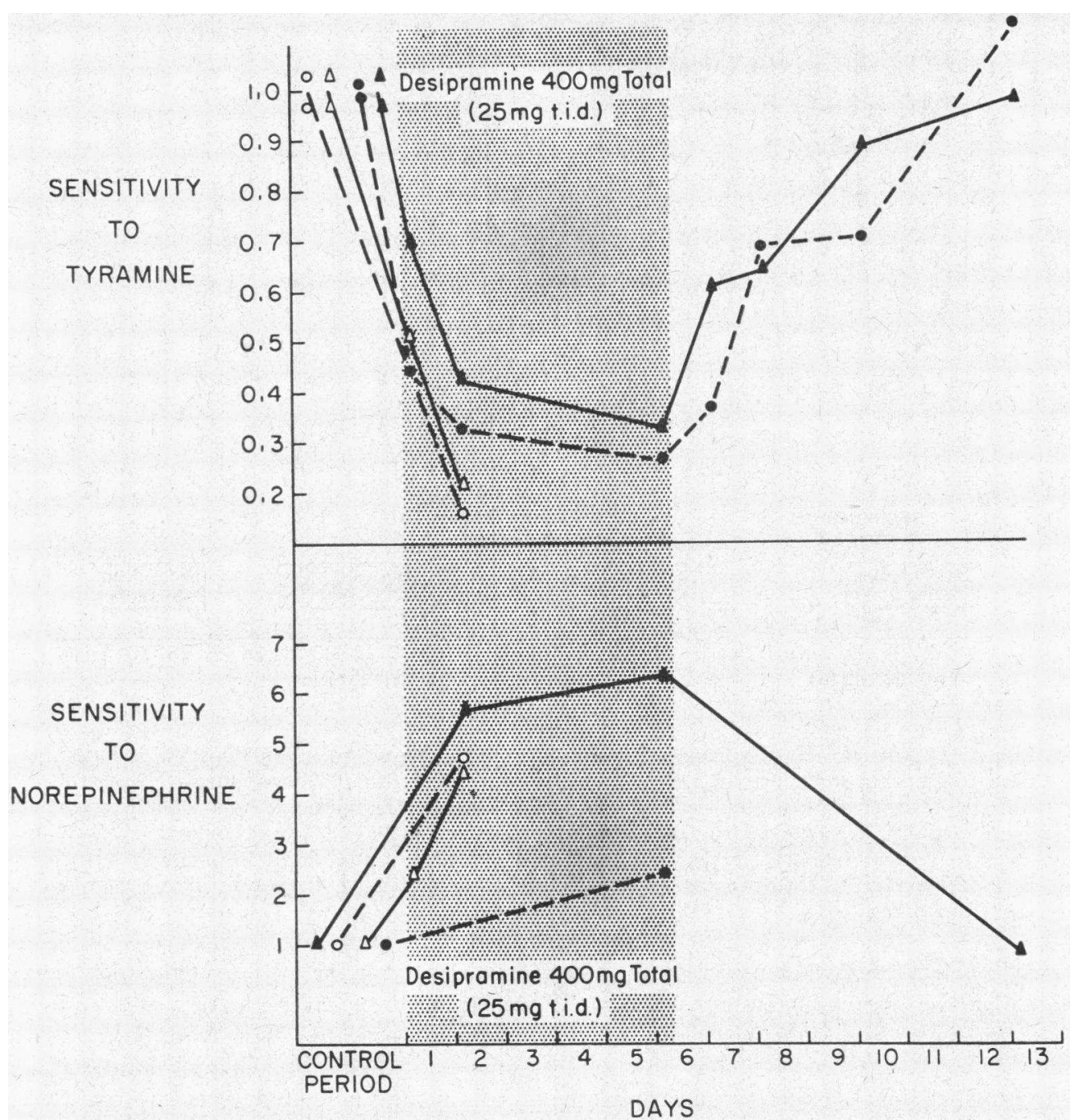

Figure 3 Blockade by desipramine of the norepinephrine transport system in peripheral adrenergic neurons. The ordinate represents the ratio of the average control to treatment dose of tyramine or norepinephrine required to increase systolic blood pressure $25 \mathrm{~mm} \mathrm{Hg}$. Desipramine was administered during shaded interval. Doses of pressor drugs on control days were: tyramine $(\mathrm{mg})-1.45,1.55 \bigcirc---\bigcirc ; 2.95,3.10 \triangle---\triangle ; 2.90,3.00 \bullet---\bullet ; 5.70,5.40$ $\Delta---\boldsymbol{\Delta} ;$ norepinephrine $(\mu \mathrm{g} / \mathrm{min})-8.8 \quad \mathrm{O}_{---} \mathrm{O} ; 9.30 \Delta---\Delta ; 2.35 \quad \bullet---\bullet ; 11.6$ $\boldsymbol{\Delta}-\boldsymbol{-} \boldsymbol{- \boldsymbol { \Delta }}$.

(relative to control) during therapy with guanethidine plus desipramine any greater than the increase seen in six other patients on desipramine alone in various doses. Finally, $5 \mathrm{mg}$ of phentolamine was given intravenously to one patient (L. J.) at the time when guanethidine's antihypertensive effect had been reversed by desipramine. This $\alpha$-adrenergic blocker lowered her blood pressure by only $30 / 11 \mathrm{~mm} \mathrm{Hg}$, clearly within the range of reduction seen in normal subjects and patients with hypertension after this dose (6) and unlike the response expected when the blood pressure is maintained by catecholamine excess.
In two studies, chlorpheniramine in clinical doses (12 or $16 \mathrm{mg}$ daily) affected pressor responses to tyramine and norepinephrine minimally if at all.

\section{DISCUSSION}

The antagonism of the antihypertensive effects of guanethidine, bethanidine, and debrisoquin by desipramine and protriptyline has obvious therapeutic implications. That other tricyclic antidepressants such as amitriptyline and nortriptyline also act as antagonists seems likely. 


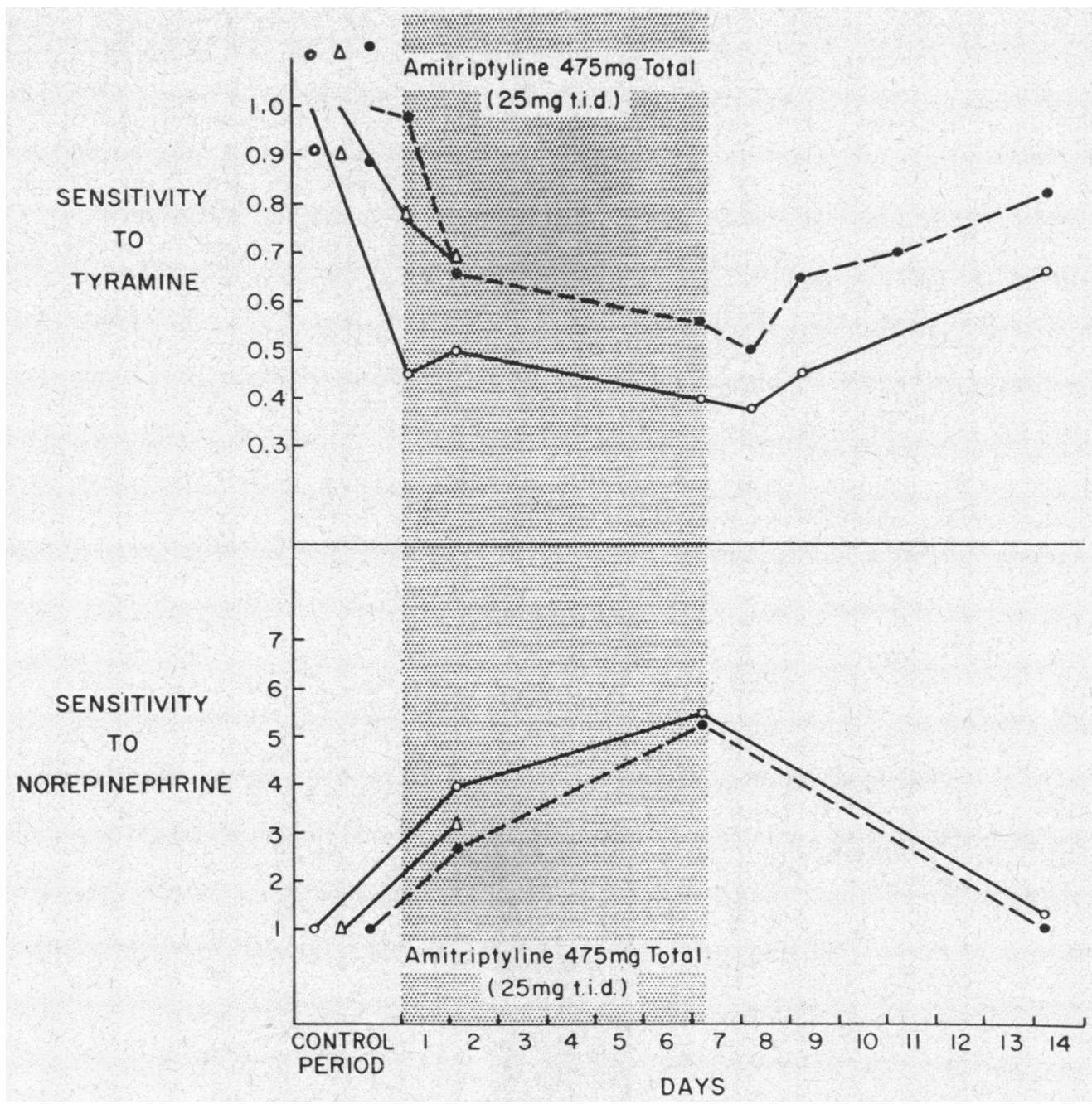

FIGURE 4 Blockade by amitriptyline of the norepinephrine transport system in peripheral adrenergic neurons. See Fig. 3 for details. Doses of pressor drugs on control days were: tyramine (mg) $-2.00,2.70 \bigcirc---\bigcirc ; 3.15,3.85 \Delta---\Delta ; 4.45,3.45 \bullet---\bullet$; norepinephrine $(\mu \mathrm{g} / \mathrm{min})-11.4 \mathrm{O}---\mathrm{O} ; 5.6 \triangle---\Delta ; 11.5 \bullet---\bullet$.

In addition to obtaining data on the clinical significance of desipramine's interactions with guanethidine, the present and related investigations ${ }^{1}$ have clarified the mechanism of the drug-drug antagonism and have defined the mechanism of the highly selective pharmacologic effects of guanethidine on adrenergic neurons. Guanethidine and related "adrenergic neuron blocking drugs" are in fact general inhibitors of nerve and muscle function since they will also block cholinergic nerves and skeletal muscle $(7,8)$. Previous work has suggested that inhibition of adrenergic neuron transmission in vivo is due to concentration of the drugs within adrenergic tissues (9-11). Guanethidine, bethanidine, and debrisoquin have been shown to be taken up by adrenergic tissues against a concentration gradient by an energy-requiring transport mechanism located in the adrenergic neuron membrane. ${ }^{1}$ Uptake of the guanidinium antihypertensive agents is inhibited competitively by norepinephrine, tyramine, desipramine, and one another. Antagonism of the catecholamine-depleting effect of guanethidine on the guinea pig heart by desipramine in vivo is associated with inhibition of uptake of guanethidine by the heart. ${ }^{2}$ Thus, guanethi-

\footnotetext{
${ }^{2}$ In addition to preventing guanethidine's uptake by the adrenergic neuron, desipramine also inhibits the hepatic microsomal metabolism of guanethidine in the rat. Mitchell, J. R., and J. A. Oates. 1970. Guanethidine and related agents. II. Hepatic microsomal metabolism and its inhibition by drugs. J. Pharmacol. Exp. Ther. 172: 108. This dual interaction must be considered when interpreting data on guanethidine-desipramine relationships in vivo.
} 
dine and related drugs block adrenergic neurons selectively because they are concentrated within these neurons by the membrane transport system that pumps norepinephrine into the neuron after its physiologic release. The necessity of the transport system for guanethidine's action is shown by the loss of guanethidine's in vivo effect when its uptake is inhibited.

The demonstration that tyramine and norepinephrine are taken up by the same transport process as the guanidinium antihypertensive agents provided the rationale for a convenient method of evaluating the effect of the tricyclic antidepressants on the transport pump in peripheral adrenergic neurons in man. Inhibition of the uptake of tyramine into the neuron should block the pressor effect of the indirectly-acting amine. Conversely, the pressor effect of norepinephrine should be potentiated because its action is terminated by the pump. The demonstrated inhibition of response to tyramine and potentiation of response to norepinephrine indicate that the small doses of desipramine, protriptyline, and amitriptyline employed clinically will block the norepinephrine pump (and guanethidine uptake) in man. The duration of desipramine's blockade of the pump is in accord with the delay in the reappearance of the guanidinium's antihypertensive effects after stopping administration of desipramine.

Localization of the antidepressants' antagonism of guanethidine to the norepinephrine pump in adrenergic neurons explains desipramine's failure to antagonize methyldopa, because the entry of this amino acid into sympathetic nerves does not depend on the pump. The slow rate at which the antihypertensive action of guanethidine was reversed also is consistent with the idea that desipramine blocks further uptake of guanethidine

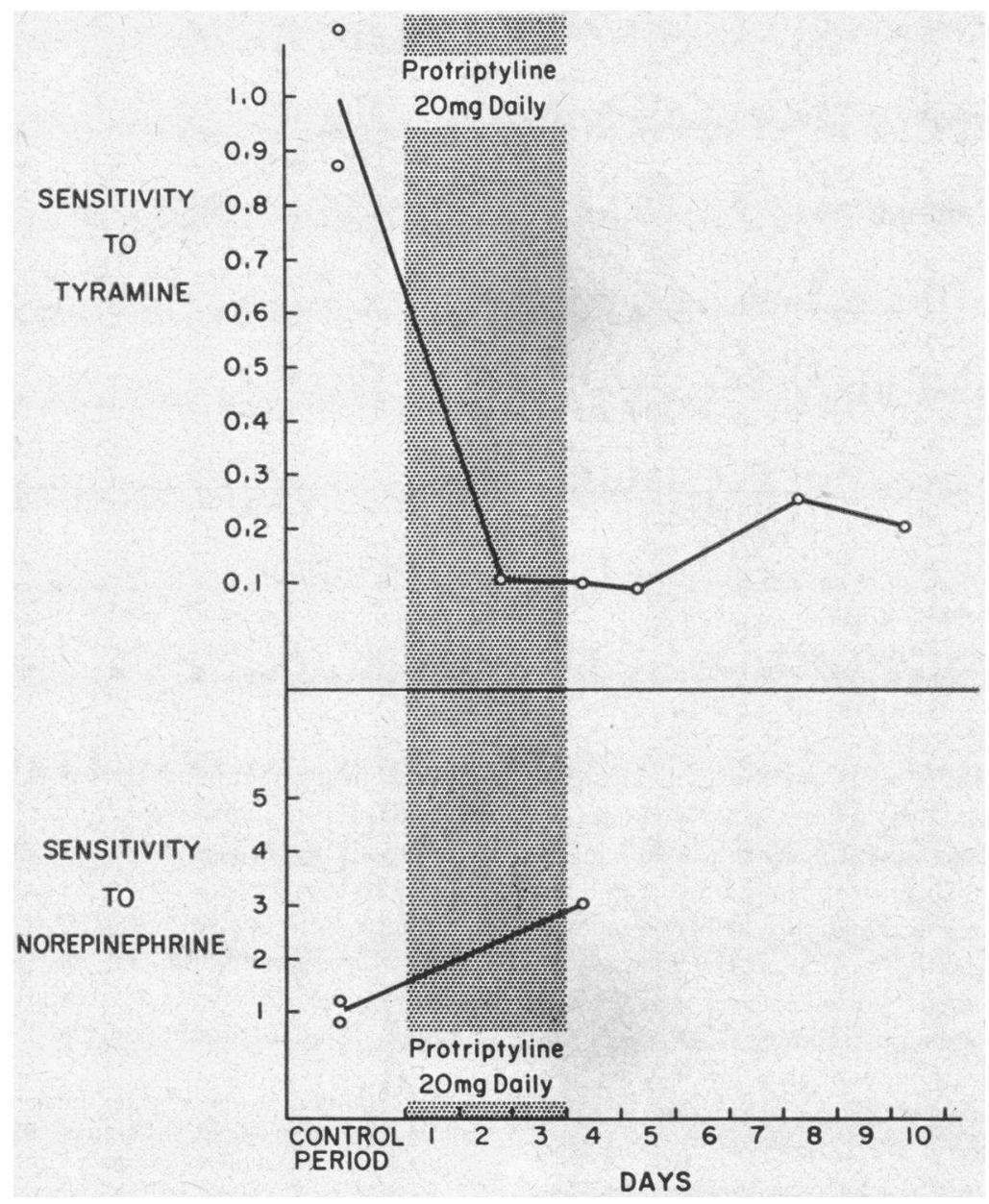

FIGURE 5 Blockade by protriptyline of the norepinephrine transport system in peripheral adrenergic neurons. See Fig. 3 for details. Doses of pressor drugs on control days were: tyramine $(\mathrm{mg}) 3.00,4.00$; norepinephrine ( $\mu \mathrm{g} /$ min) $2.65,3.80$. 


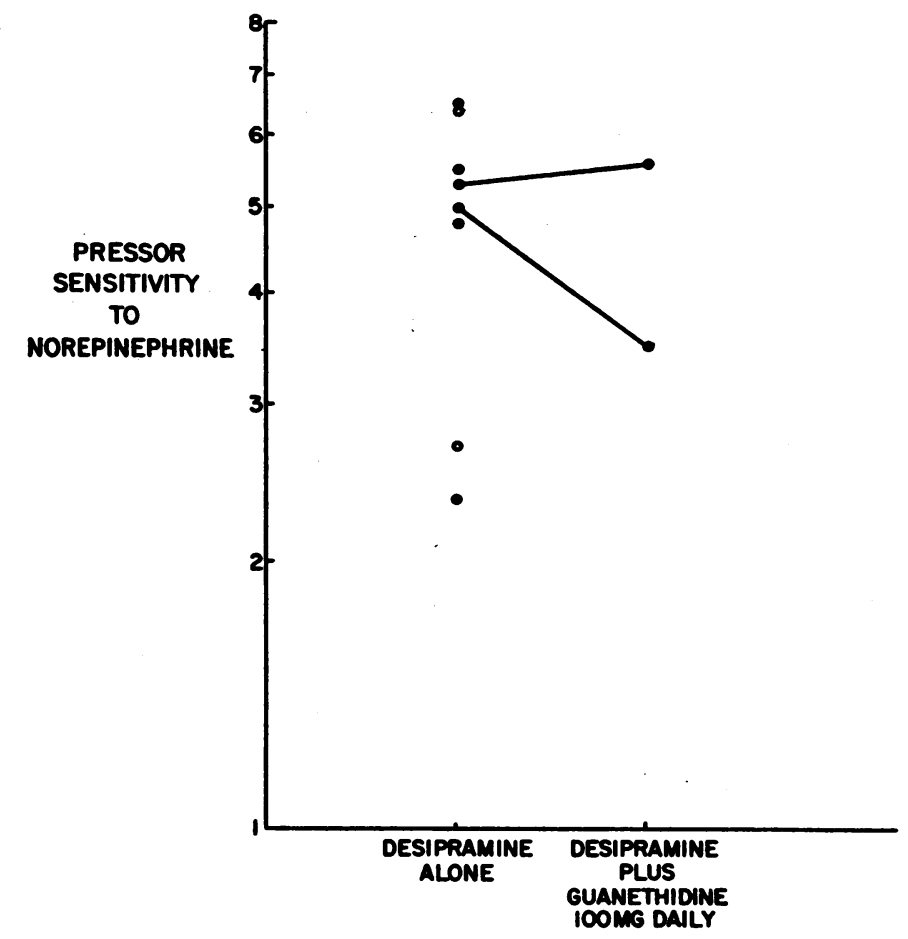

FIGURE 6 The effect on pressor sensitivity to norepinephrine of adding $100 \mathrm{mg}$ of guanethidine daily to the regimen of patients receiving desipramine. The dose of desipramine was $75 \mathrm{mg}$ daily (C) or $200 \mathrm{mg}$ daily (O). The lines connect values obtained in the same patient. Pressor sensitivity was determined after at least 5 days of desipramine administration and on the 5 th day of guanethidine administration together with resipramine.

into the neuron and the rate at which the hypotensive agent loses its effect is dependent on the duration of action of that drug already in the neuron. Thus, the effects of bethanidine and debrisoquin, drugs with short durations of action, were reversed more rapidly by desipramine. In addition, the slow onset of the antagonism of guanethidine, is in accord with the failure of Gulati, Dave, Gokhale, and Shah (12) to find antagonism of guanethidine by imipramine at the end of $12 \mathrm{hr}$.

Another possible mechanism was considered to explain the increase in blood pressure when desipramine is added to guanethidine. Because desipramine and guanethidine each potentiate norepinephrine's action when given alone, it might be postulated that the two together could cause sufficient enhancement of norepinephrine's response to raise blood pressure. The differing rates of reversal of the short- and long-acting guanidiniums suggests that such dual supersensitivity is not the mechanism of the blood pressure rise. Further, the administration of large doses of guanethidine to patients already on desipramine did not elevate the blood pressure and did not produce greater supersensi- tivity to infused norepinephrine than that seen with desipramine alone.

Methylphenidate, some phenothiazines, and certain antihistamines block guanethidine's action in experimental animals (3), presumably via the same mechanism as that of the antidepressants. Whether these observations have clinical relevance remains to be determined. The tyramine-norepinephrine pressor tests can be used to evaluate the potency of such drugs as inhibitors of the norepinephrine transport system in patients, thereby predicting clinical antagonism of the guanidinium antihypertensives. The studies with chlorpheniramine, for example, indicate that concomitant administration of this antihistamine and the guanethidine-like drugs should not be a clinical hazard.

Interactions of the tricyclic antidepressants with other classes of drugs also can be predicted from the present studies. The evidence for inhibition of the norepinephrine pump indicates that the potency of indirectlyacting pressor agents such as mephentermine will be diminished in patients receiving these antidepressant drugs. 
Several mechanisms of clinical drug interactions are known (13), including induction and inhibition of the enzymes that metabolize drugs, displacement of drugs from binding sites on plasma proteins, and alterations in absorption and excretion. The present investigation presents a new mechanism for drug-drug interactions in man-inhibition of the transport of a drug to its site of action.

\section{ACKNOWLEDGMENTS}

We gratefully acknowledge the advice of Charles F. Federspiel, Ph.D., regarding the statistical analyses. The drugs used in this study were generously provided by Dr. S. T. Bloomfield, Burroughs Wellcome \& Co., Tuckahoe, N. Y. (bethanidine), Dr. W. B. Abrams, Hoffman-La Roche, Inc., Nutley, N. J. (debrisoquin), Dr. L. B. Hobson, Shering Corporation, Bloomfield, N. J. (placebos for chlorpheniramine), Dr. E. Grunwaldt, Geigy Pharmaceuticals, Ardsley, N. Y. (desipramine and its placebo), Dr. S. C. Strickland, Merck Sharp \& Dohme, West Point, Pa. (protriptyline), and E. L. Foltz, Merck Sharp \& Dohme (tyramine).

These investigations were supported by Grants GM 15431, HE 05545, HE 10842, FR 00095, and by the Burroughs Wellcome Fund and the Vivian B. Allen Foundation.

\section{REFERENCES}

1. Mitchell, J. R., L. Arias, and J. A. Oates. 1967. Antagonism of the antihypertensive action of guanethidine sulfate by desipramine hydrochloride. J. Amer. Med. Ass. 202: 973 .

2. Leishman, A. W. D., H. L. Matthews, and A. J. Smith. 1963. Antagonism of guanethidine by imipramine. Lancet. 1: 112 .
3. Stone, C. A., C. C. Porter, J. M. Stavorski, C. T. Ludden, and J. A. Totaro. 1964. Antagonism of certain effects of catecholamine-depleting agents by antidepressant and related drugs. J. Pharmacol. Exp. Ther. 144: 196.

4. Kaumann, A., N. Basso, and P. Aramendia. 1965. The cardiovascular effects of $\mathrm{N}-(d$-methylaminopropyl-iminodibenzyl)- HCL (desmethylimipramine) and guanethidine. J. Pharmacol. Exp. Ther. 147: 54.

5. Li, J. C. R. 1964. Statistical Inference. Edwards Brothers, Inc., Ann Arbor, Mich. 1: 252.

6. Taylor, S. H., G. R. Sutherland, G. J. MacKenzie, H. P. Stannton, and K. W. Donald. 1965. The circulatory effects of intravenous phentolamine in man. Circulation. 31: 741.

7. Boura, A. L., and A. F. Green. 1965. Adrenergic neurone blocking agents. Annu. Rev. Pharmacol. 5: 183.

8. Chang, C. C., T. F. Chen, and H. C. Cheng. 1967. On the mechanism of neuromuscular blocking action of bretylium and guanethidine. J. Pharmacol. Exp. Ther. 158: 89 .

9. Boura, A. L., and A. F. Green. 1963. Adrenergic neurone blockade and other acute effects caused by $\mathrm{N}$-benzyl- $\mathrm{N}^{\prime} \mathrm{N}^{\prime \prime}$ dimethylguanidine (bethanidine-BW 467C60) and its ortho-chloro derivative (BW 392C60). Brit. J. Pharmacol. Chemother. 20: 36.

10. Shanker, L. S., and A. S. Morrison. 1967. Physiological disposition of guanethidine in the rat and its uptake by heart slices. Int. J. Neuropharmacol. 4: 27.

11. Giachetti, A., M. A. Medina, and P. A. Shore. 1967. Mechanism of action of adrenergic neuronal blocking drugs. Pharmacologist. 9: 235.

12. Gulati, O. D., B. T. Dave, S. D. Gokhale, and K. M. Shah. 1966. Antagonism of adrenergic neuron blockade in hypertensive subjects. Clin. Pharmacol. Ther. 7: 510.

13. Binns, T. B. 1965. Symposium on clinical effects of interactions between drugs. Proc. Roy. Soc. Med. 58: 943. 